\title{
Particle fracture and debonding during orthogonal machining of metal matrix composites
}

\author{
A. Pramanik ${ }^{1}$ L. C. Zhang $^{2}$
}

Received: 19 July 2016/ Accepted: 3 January 2017/Published online: 20 February 2017

(C) Shanghai University and Springer-Verlag Berlin Heidelberg 2017

\begin{abstract}
This paper investigates the particle fracture and debonding during machining of metal matrix composite (MMC) due to developed stress and strain, and interaction with moving tool by finite element analysis. The machining zone was divided into three regions: primary, secondary and tertiary deformation zones. The tendency of particles to fracture in each deformation zone was investigated. The findings of this study were also discussed with respect to the experimental results available in the literature. It was found that particles at the cutting path in the tertiary deformation zone fractured as it interacted with tool. In the secondary deformation zone, particles interacted with other particles as well as cutting tool. This caused debonding and fracture of huge number of particles as those were moving up along the rake face with the chips. No particle fracture was noted at the primary deformation zone. The results obtained from finite element analysis were very similar to those obtained from experimental studies.
\end{abstract}

Keywords Particle reinforced metal matrix composite . Particle fracture $\cdot$ Particle debonding $\cdot$ Finite element analysis $\cdot$ Strain distribution

A. Pramanik

alokesh.pramanik@curtin.edu.au

1 Department of Mechanical Engineering, Curtin University, Bentley, WA 6102, Australia

2 School of Mechanical and Manufacturing Engineering, University of New South Wales, Sydney, NSW 2052, Australia

\section{Introduction}

Existing functional materials have attained their performance limits, and designers are looking to metal matrix composites (MMCs) to provide additional strength, stiffness, wear resistance and temperature capabilities required for advanced applications in aerospace, automobile, etc [1]. However, their application is somewhat restricted by poor ductility, low fracture toughness and tendency to fracture easily [2]. The complexities such as worse surface quality and higher tool wear are unavoidable during machining though MMCs inherit better mechanical properties comparing to its constituents and conventional materials [3]. Hence, research and application of MMC are increasing. During machining of MMC, fracture and debonding of very hard reinforced particles play very important roles on surface generation, tool wear and chip formation. Particle fracture and debonding are mainly controlled by tool-particle interaction, and stress, strain and strain rate developed at different locations of machining zone. Researches have investigated fracture of MMC in tensile and compression test [4]. But many phenomena such as particle fracture and debonding mechanism during machining of MMC are still little understood though there are huge researches in this field. Pramanik et al. [5] investigated tool-particle interaction and subsequent stress-strain developments during machining of MMC in detail. This paper investigates the particle fracture and debonding in detail during machining of MMC in primary, secondary and tertiary deformation zones.

\section{Modelling}

\subsection{Boundary conditions}

ANSYS/LS-DYNA version 10 was used to develop a 2D plane-stress finite element model where material 


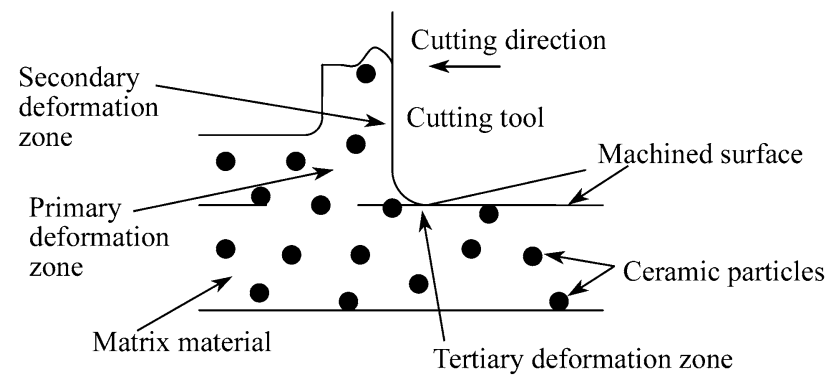

Fig. 1 Typical machining process of particle reinforced MMC [9]

continuum was based on Lagrangian formulation. Figure 1 presents the schematic of MMC machining. The tool cutting edge radius was $6 \mu \mathrm{m}$ and reinforced particle diameters were $18 \mu \mathrm{m}$. The reinforcements were constrained to a small area only around the cutting edge to keep the model size manageable. The particles were $20 \%$ by volume in this region and were assumed to be perfectly bonded with the matrix where the interface nodes of the matrix and reinforcements were tied together $[6,7]$. Thus the movements of the nodes at the interface are equal for both the matrix and reinforcements. The interface can be assumed as a postponement of the particle as it is very hard and brittle, and hence equivalent to the reinforced particles [8]. The workpiece was fully fixed on its bottom surface to eliminate rigid body motion. The cutting tool was assumed as a rigid body and moved horizontally into the workpiece at a constant speed of $50 \mathrm{~m} / \mathrm{min}$ with the cut thickness of $0.2 \mathrm{~mm}$.

The cutting speed was kept reasonably low to minimize the effect of cutting temperature on material properties. The cutting temperature is approximately $105{ }^{\circ} \mathrm{C}$ for turning of $30 \%$ (volume) $\mathrm{SiC}$ particle reinforced MMC at $50 \mathrm{~m} / \mathrm{min}$ cutting speed, $1 \mathrm{~mm}$ depth of cut and $0.1 \mathrm{~mm} / \mathrm{r}$ feed [10]. The change of material properties at this temperature is negligible [4]. In addition, a correlation between strength of MMC and cutting speed for depth of cut $1 \mathrm{~mm}$ and feed of $0.2 \mathrm{~mm} / \mathrm{r}$ shows that due to cutting speed of 50 $\mathrm{m} / \mathrm{min}$, the strength of MMC is reduced only by $0.25 \%$ [9]. This reduction of strength can be neglected to avoid complexity.

\subsection{Material model}

The MMC work material was 6061 aluminum alloy reinforced with silicon carbide particles. A temperature-independent plastic kinematic material model (from ANSYS/ LS-DYNA [11]) and associative flow rule were used for the matrix. Strain rate was accounted for using the CowperSymonds model which scaled the yield stress by a strain rate dependent factor. According to ANSYS/LS-DYNA [11], the equation to calculate yield stress in the plastic kinematic material model is given below.
$\sigma_{y}=\left(1+\left(\frac{\dot{\varepsilon}}{C}\right)^{\frac{1}{P}}\right)\left(\sigma_{0}+\beta E_{\mathrm{p}} \varepsilon_{\mathrm{peff}}\right)$,

where

$E_{\mathrm{p}}=\frac{E_{\mathrm{tan}} E}{E-E_{\mathrm{tan}}}$.

$\sigma_{y}$ is yield stress, $\sigma_{0}$ initial yield stress, $\dot{\varepsilon}$ strain rate, $C$ and $P$ the cowper-symonds strain rate parameters, $\varepsilon_{\text {peff }}$ effective plastic strain, $\beta$ hardening parameter $(\beta=0$ for kinematic hardening and $\beta=1$ for isotropic hardening [11]), $E_{\mathrm{p}}$ plastic hardening modulus, $E_{\text {tan }}$ tangent modulus, $E$ modulus of elasticity. The material properties of the matrix were based on the commonly accepted values $\sigma_{0}=125 \mathrm{MPa}$, $E=71 \mathrm{GPa}, E_{\tan }=1.48 \mathrm{GPa}$ from Refs. $[12,13]$. The values of cowper-symonds strain rate parameters $(C=6500, P=4)$ for alluminium alloy were taken form ANSYS/LS-DYNA manual [11]. In this study kinematic hardening was considered as a first assumption because of comparatively low plastic hardening modulus (1.51 GPa) of matrix material to investigate the strain rate effect.

A chip separation criterion available with ANSYS/LSDYNA for this material model was used in the simulation. According to this criterion, chip separation occurs when the strain value of the leading node is greater than or equal to a limiting value. Based on the work for aluminium alloys reported in Refs. [6, 7], the limiting strain was taken as 1 . When an element of matrix material reached the limiting strain value, the corresponding element would be deleted. Additionally, $\mathrm{SiC}$ particles were also treated as plastic kinematic material and a fracture criterion was calculated based on fracture toughness of $\mathrm{SiC}$ but its yield stress was set artificially high so that it behaved elastically until fractured. The following procedure was followed to calculate fracture strain of $\mathrm{SiC}$ particles.

According to Zhu and Kishawy [8] and Nan and Clarke [14], the particle is considered to break if the stress in the particle exceeds the Griffith criterion, where the fracture stress is given by

$\sigma=\frac{K_{\mathrm{c}}}{\sqrt{d}}$

where $K_{\mathrm{c}}$ is fracture toughness and $d$ is the diameter of $\mathrm{SiC}$ particles. Then the fracture strain of the particle was calculated using Hooks law as given below

$\varepsilon=\frac{\sigma}{E}$.

The typical stress-strain curve considered in the study is given in Fig. 2. The material properties of the particles were based on the commonly accepted values: modulus of elasticity $400 \mathrm{GPa}$ and Poisson's ratio 0.17 . 


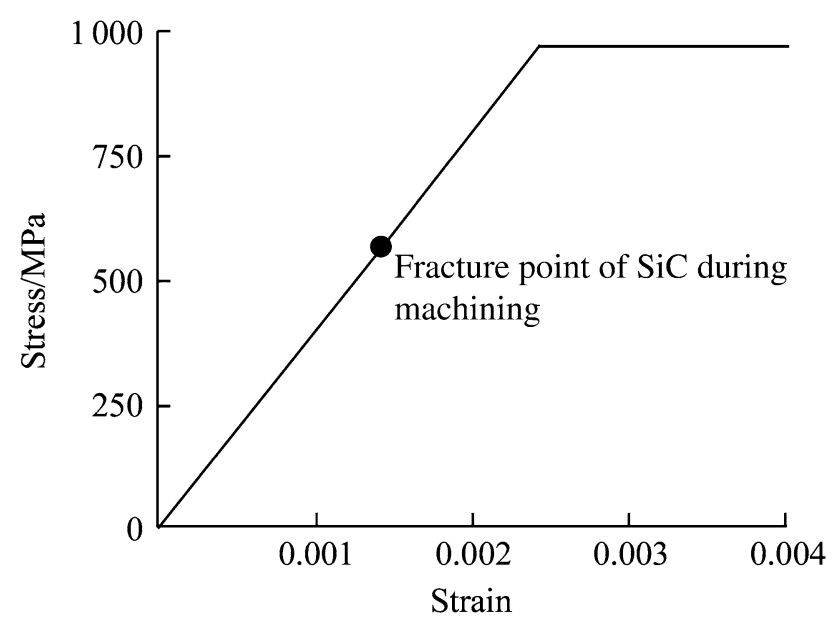

Fig. 2 Stress versus strain curve for $\mathrm{SiC}$

\subsection{Contacts during machining}

Along with the general contact family in ANSYS/LSDYNA, the automatic contact options are the most commonly used contact algorithms for its versatility. Hence, 2D automatic contact was chosen for this simulation. In order to consider the effect of friction along the tool-chip interface, Coulomb friction model was employed, defined as

$\tau_{\lim }=\mu P+b$,

$|\tau| \leqslant \tau_{\lim }$,

whrere $\tau_{\lim }$ is limiting shear stress, $\tau$ equivalent shear stress, $P$ the contact pressure, $\mu$ friction coefficient and
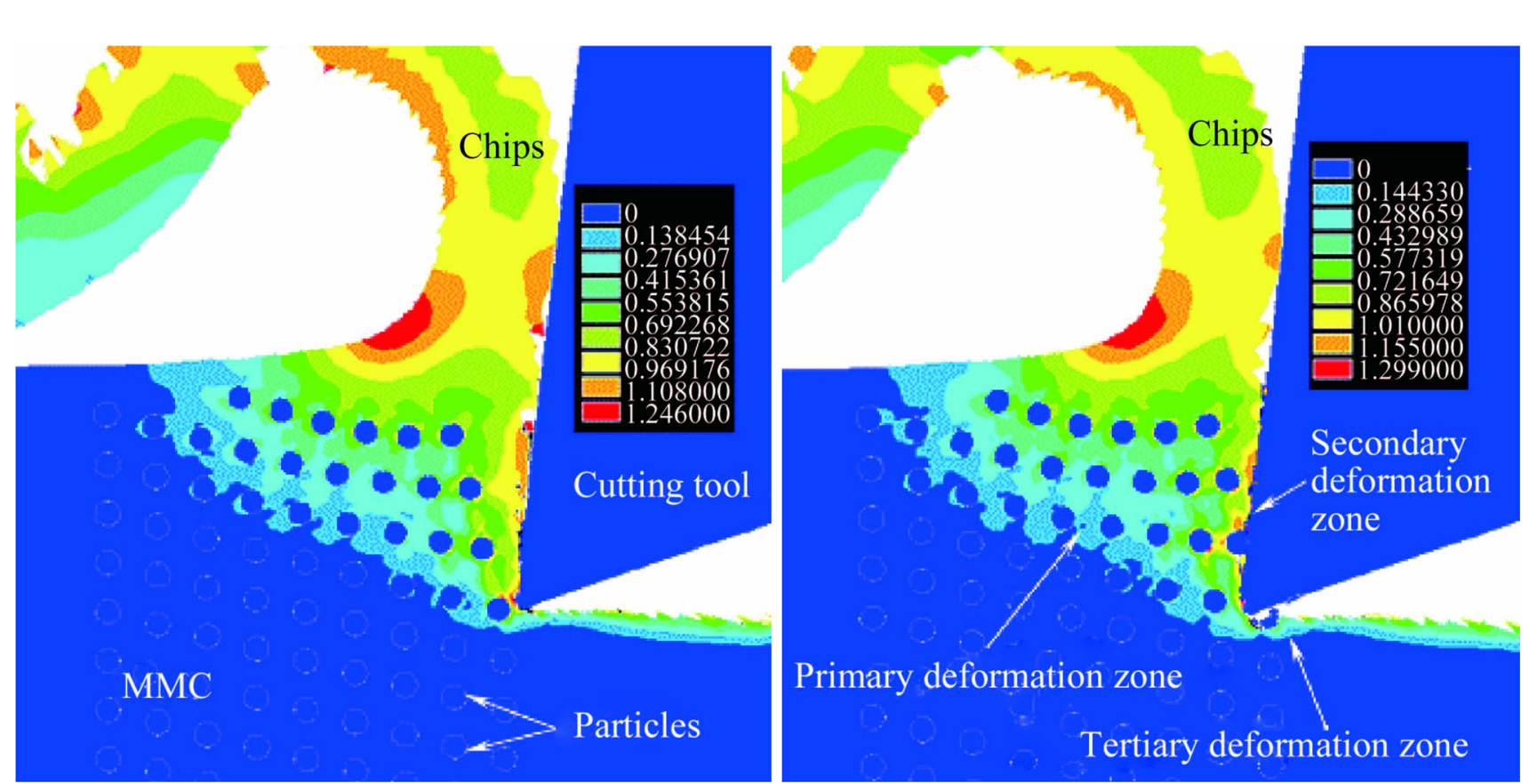

$b$ cohesion sliding resistance (sliding resistance with zero normal pressure). According to ANSYS/LS-DYNA manual [11], two contacting surfaces can carry shear stresses up to a certain magnitude across their interface before they start sliding relative to each other (sticking state). When $\tau>\tau_{\text {lim }}$, the two surfaces will slide relative to each other (sliding state). For machining conditions, $b$ was assumed to be zero. The limiting shear stress $\tau_{\lim }=202 \mathrm{MPa}$ and coefficient of friction $\mu=0.62$ were based on the study reported in Ref. [9].

\section{Results and discussions}

In this investigation, particles will be divided into three categories: primary particles located in the primary deformation zone, secondary particles located in secondary deformation zone and tertiary particles located in tertiary deformation zone. Figures 3 and 4 depict the contours of the von Mises plastic strain in the MMC material at different stages of machining. Plastic deformation is observed as the workpiece material enters into the primary deformation zone. The distribution of plastic strain is in layered pattern with a highly strained zone at the tool-chip interface. Plastic strain has clearly increased as the material moves into the chip. However, the particles are well discerned because no plasticity exists in purely elastic particles. Moreover, the deformation patterns are different compared to those of monolithic metal during machining in that the presence of discrete particles causes banded structure and dramatically fragments the plastic field.

Fig. 3 Initial stages of machining 


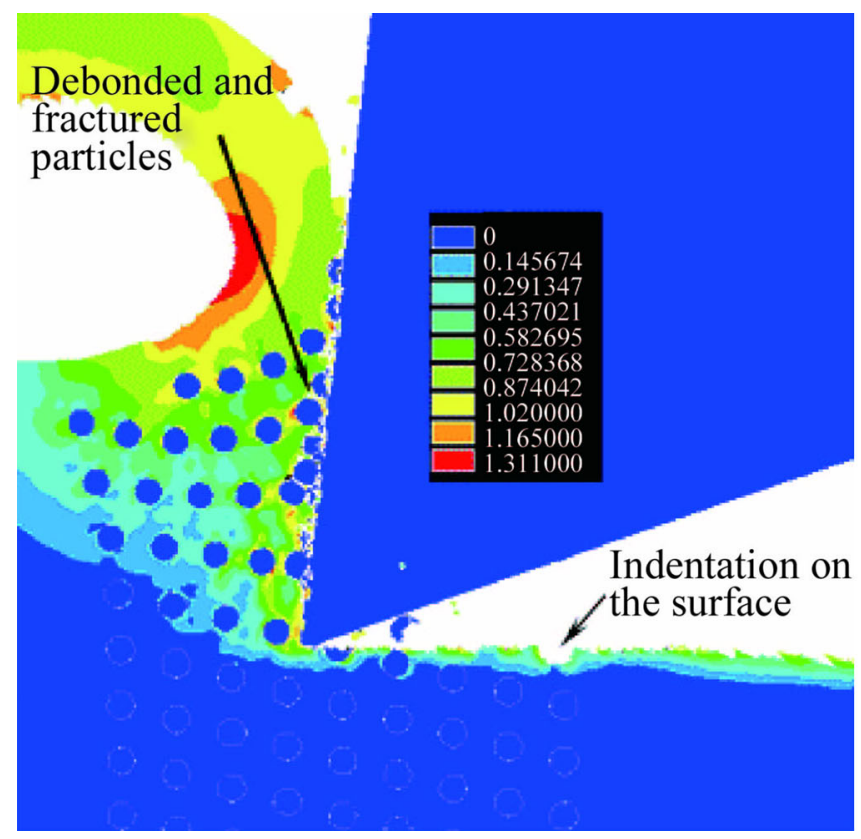

Fig. 4 Final stages of machining

\subsection{Particles at primary deformation zone}

At first, particles move in the cutting direction with the surrounding matrix due to the movement of the tool. As the rake face of the tool approaches, particle interface becomes highly strained. Due to the ability of the matrix to deform plastically and particle's inability, the matrix material experiences very high plastic strain. The strain is very low around the reinforced particles at the entry to the primary deformation zone. The strain increases progressively as the MMC goes well inside the primary deformation zone. This means that the intensity of strain increases in the MMC from undeformed zone to the primary deformation zone gradually. No fracture of particles is noted in this zone. The particles in the top part of primary deformation zone are further strained and go into the chip with the advancement of the cutting tool. However, the particles in the bottom part of the primary deformation zone are further strained and enter into the secondary deformation zone.

\subsection{Particles at secondary deformation zone}

Part of strained MMC enters secondary deformation zone where it is severely strained and strain localization at the matrix-particle interface occurs. With further advancement of the tool, particles debond partially, interact with the tool and nearby particles, and move with the chip along the rake face. Most of the particles debond completely from matrix material and fracture while passing through the secondary deformation zone (see Figs. 3 and 4).

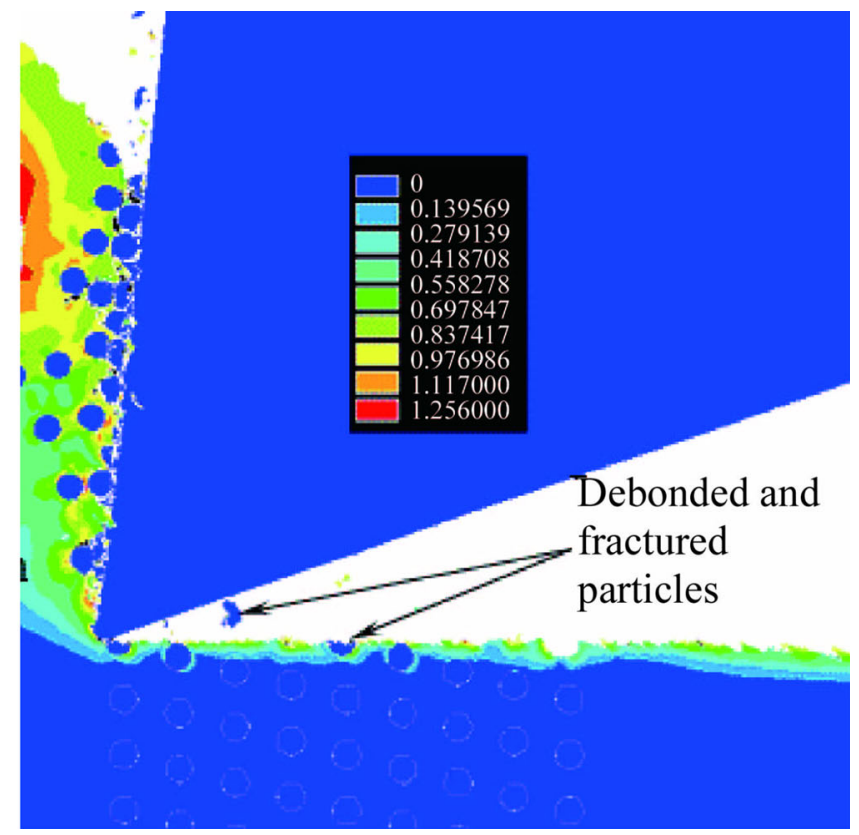

\subsection{Particles at tertiary deformation zone}

Initially, for a particle at lower part of the cutting edge, the matrix in between particle and tool, and that at upper part of particle are highly strained. With the progression of cutting, tool interacts with the particle at cutting edge and the particle is debonded and fractured. It then slides and indents into the new workpiece surface causing high plastic strain in the surrounding matrix. As the tool moves further, the particle is released from matrix leaving a ploughed hole in the surface with high residual strain. A particle located at the upper part of cutting edge moves up slightly with the advancement of tool. In this case, the strain in the matrix in between the particle and tool is high and the particles start to fracture as soon as those come in contact with the cutting tool. Then the deboned and fractured particles slide along the rake face with the chip.

The interfaces of particles in the workpiece far below the cutting edge do not experience any plasticity during machining. But those situated immediately below the cutting edge are subjected to plastic deformation when the tool passes over them. The banded pattern of the strain field is fragmented in the interface of particles just below the tool cutting edge. With further advancement of the tool, most of the interface of the particle is plastically deformed. Additionally, the matrix at the matrix-tool cutting edge interface is plastically strained. The particles below the cutting edge seem to act like indenters due to their interaction with the tool. In these regions the matrix can be seen to plastically deform to a greater depth. 


\subsection{Discussions}

It is proved from several studies that particle fracture occurs during machining of MMCs. The number of particle fracture depends on developed stress and strain, properties of matrix and particles, and size of particles. The behaviour of particle fracture completely depends on its size in a given manufacturing process. Probability of particle fracture is much higher for larger particles comparing to that of smaller particles. Quan et al. [15] noted large quantity of harmful dust after machining MMC with larger particle size but those disappeared during machining MMC with smaller particle size. This observation reveals two main facts: (i) this dust is due to fracture of particles in tool-chip and tool-workpiece interfaces; (ii) huge number of particles are accumulating at the tool-chip interface and those particles are fractured and debonded.

\subsubsection{Particles at primary and secondary deformation zones}

The beginning of flow of particles in the chip root region was observed at the start of MMC machining and with further advancement of the tool, the inter particle distance as well as distance between particle and tool decreased. Cracking occurs from partial debonding of particles from the matrix near the secondary shear zone in front of the cutting tool (see Figs. 3 and 4). The interfaces of reinforcement particles fail as they go through the secondary shear zone. Thus, the partially debonded particles interact with nearby particles as well as with tool which results in further debonding and particles fracture on the rake face. These particles slide continuously over the rake face and go into the chip. During sliding they may scratch the tool rake face leading to abrasive wear. This is different to the flank where impact and discontinuous sliding of particles are noted. Hence smoother wear at rake is expected. After sliding few hundred microns along rake face, some particles are dislodged from chips while others remain in chips. The above mentioned phenomena were noted in experimental investigation by Hung et al. [16] who used a quick stop device. They reported cracks due to debonding of particles in front of tool. In the chip root region, reinforced particles were observed to align along the shear plane. ElGallab and Sklad [17] studied chips obtained from machining MMC, observed the flow lines of particles and debonded particles in the chips.

Almost all researchers noted comparatively high tool wear during machining of MMC with any tool. For diamond tools it is reported that wear at rake face is also abrasive but smoother than that at flank face [18-20]. The rake face wear can be attributed to frequent interactions between the rake face and hard particles, and the continuous sliding of these particles along the rake face (see Figs. 3, 4).

\subsubsection{Particles at tertiary deformation zone}

From the finite element simulations it is observed that particles in the lower part of the cutting edge initially interact with cutting edge, fracture and are then debonded by leaving a cavity on the machined surface. They also take part in ploughing of the newly generated work surface. The particles in the upper part of the cutting edge slide over the rake face. It is expected that, with the increase of cutting speed, the impact between tool and particles increases.

Repeated interaction, which generates high stress concentration, and sliding of particles on lower part of cutting edge and tool flank may create groves, cracks and pull out of tool material particles from cutting edge and flank face during machining of MMC. Several researchers $[18,19,21]$ reported the grooves and chipping (due to repeated impact between tool edge and particles) on the cutting edge and flank face after machining MMCs. The damage of the tool cutting edge/flank was attributed to abrasion [18, 22-24] and pulled out of tool material grains from cutting edge and flank face of the tool [21]. It was also reported that flank wear increased with speed [25, 26] and at high speeds, chipping of cutting edge became prominent [26]. Under these conditions, impact between particle and tool increases which induces easier fracture causing chipping at the cutting edge.

After interacting with the cutting edge and flank face, particles on the lower part of the cutting edge are debonded and pulled out leaving cavities on the machined surface. Zhang et al. [27], Yan and Zhang [28] who studied MMCs by scratching tests observed pulling out of reinforcement particles and cavities on the scratched surface. Similar observations were also reported in an experimental study by El-Gallab and Sklad [17] who machined SiC particulate reinforced MMC.

Direct tool-particle interactions do not happen when particles are well below the cutting edge but the tool movement causes a significant change in stress in the particles and stress/strain in the surrounding matrix. The degree of plastic deformation of the newly generated surface depends on the particle orientations. These cause inhomogeneous deformation and flow of matrix in the MMC. Thus localized hardening of MMC surface can be expected after machining. In this scenario the effect of cutting tool edge on the workpiece surface may resemble the indentation of an MMC. Pramanik et al. [7] studied micro-indentation of MMC and noted inhomogeneous deformation of matrix material due to presence of particles. Particle locations were found to play an important role on the degree of plastic deformation of matrix material. 
Matrix at particle-matrix interface and that between particle and tool were shown to be highly strained. These phenomena were also observed by other researchers, e.g., Monaghan and Brazil [6] who numerically studied micromechanics associated with the machining of particle reinforced MMCs noted inhomogeneous matrix flow in the machined surface which was controlled by reinforced particles.

\section{Conclusions}

This study gives in-depth understanding on the particle debonding and fracture during machining particle reinforced MMC. The following conclusions can be drawn from the above analysis.

(i) Particle debonding and fracture during machining of MMC occur at secondary and tertiary deformation zones. However, no particle fracture is noted at the primary deformation zone.

(ii) In addition to tool-particle interaction, interaction among the particles stimulates debonding and fracture of particles in the secondary deformation zone. The sharp edges of the fractured particles in the tool-chip interface contribute to tool wear significantly during machining of MMCs.

(iii) The MMC experiences much higher strain in secondary and tertiary deformation zones comparing to that in primary deformation zone.

(iv) The tool-particle interactions, fracture and debonding of particles damage the machined surface as well as introduce localized strain hardening in the machined material.

\section{References}

1. Pramanik A (2014) Developments in the non-traditional machining of particle reinforced metal matrix composites. Int $\mathrm{J}$ Mach Tools Manuf 86:44-61

2. Needleman A, Nuti SR, Suresh S et al (1993) Matrix, reinforcement, and interfacial failure. In: Davim JP (eds) Fundamentals of metal-matrix composites (A 95-25875 06-24). Butterworth-Heinemann, Stoneham, pp 233-250

3. Pramanik A, Arsecularatne J, Zhang L (2008) Machining of particulate-reinforced metal matrix composites. In: machining. Springer, London, pp 127-166

4. Clyne TW, Withers PJ (1993) Fracture process and failure mechanism. In: Davis EA, Ward IM (eds) An introduction to metal matrix composites. Press syndicate of the University of Cambridge, Cambridge

5. Pramanik A, Zhang L, Arsecularatne J (2007) An FEM investigation into the behavior of metal matrix composites: tool-particle interaction during orthogonal cutting. Int J Mach Tools Manuf 47(10):1497-1506
6. Monaghan J, Brazil D (1997) Modeling the sub-surface damage associated with the machining of a particle reinforced MMC. Comput Mater Sci 9(1):99-107

7. Pramanik A, Zhang L, Arsecularatne J (2007) Micro-indentation of metal matrix composites - an FEM analysis. Key Eng Mater 340:341

8. Zhu Y, Kishawy H (2005) Influence of alumina particles on the mechanics of machining metal matrix composites. Int $\mathrm{J}$ Mach Tools Manuf 45(4):389-398

9. Pramanik A, Zhang L, Arsecularatne J (2006) Prediction of cutting forces in machining of metal matrix composites. Int J Mach Tools Manuf 46(14):1795-1803

10. Reddy PR, Sriramakrishna A (2002) Analysis of orthogonal cutting of aluminium-based composites. Def Sci J 52(4):375-383

11. ANSYS/LS-DYNA, ANSYS/LS-DYNA reference manual, Release 10, Livermore Software Technology Corporation, 7374 Las Positas Road, Livermore, CA 94551

12. Meijer G, Ellyin F, Xia Z (2000) Aspects of residual thermal stress/strain in particle reinforced metal matrix composites. Compos Part B Eng 31(1):29-37

13. Long S, Zhou Y (2005) Thermal fatigue of particle reinforced metal-matrix composite induced by laser heating and mechanical load. Compos Sci Technol 65(9):1391-1400

14. Nan CW, Clarke D (1996) The influence of particle size and particle fracture on the elastic/plastic deformation of metal matrix composites. Acta Mater 44(9):3801-3811

15. Quan Y, Zhou Z, Ye B (1999) Cutting process and chip appearance of aluminum matrix composites reinforced by $\mathrm{SiC}$ particle. J Mater Process Technol 91(1):231-235

16. Hung NP, Loh N, Venkatesh V (1999) Machining of metal matrix composites. In: Jahanmir S, Ramulu M, Koshy P (eds) Machining of ceramics and composites. Marcel Dekker, New York

17. El-Gallab M, Sklad M (1998) Machining of Al/SiC particulate metal matrix composites: part II: workpiece surface integrity. J Mater Process Technol 83(1):277-285

18. El-Gallab M, Sklad M (1998) Machining of Al/SiC particulate metal-matrix composites: part I: tool performance. J Mater Process Technol 83(1):151-158

19. Ding X, Liew W, Liu X (2005) Evaluation of machining performance of MMC with PCBN and PCD tools. Wear 259(7): $1225-1234$

20. Heath PJ (2001) Developments in applications of PCD tooling. J Mater Process Technol 116(1):31-38

21. Chambers A (1996) The machinability of light alloy MMCs. Compos Part A Appl Sci Manuf 27(2):143-147

22. Jaspers S, Dautzenberg J (2002) Material behaviour in metal cutting: strains, strain rates and temperatures in chip formation. J Mater Process Technol 121(1):123-135

23. Lin CB, Hung YW, Liu WC et al (2001) Machining and fluidity of $356 \mathrm{Al} / \mathrm{SiC}_{(\mathrm{p})}$ composites. J Mater Process Technol 110(2): 152-159

24. Davim JP (2002) Diamond tool performance in machining metalmatrix composites. J Mater Process Technol 128(1):100-105

25. Kılıçkap E, Çakır O, Aksoy M et al (2005) Study of tool wear and surface roughness in machining of homogenised SiC-p reinforced aluminium metal matrix composite. J Mater Process Technol 164:862-867

26. Ciftci I, Turker M, Seker U (2004) Evaluation of tool wear when machining SiC p-reinforced Al-2014 alloy matrix composites. Mater Des 25(3):251-255

27. Zhang Z, Zhang L, Mai YW (1995) Particle effects on friction and wear of aluminium matrix composites. J Mater Sci 30(23):5999-6004

28. Yan C, Zhang L (1994) Single-point scratching of 6061 Al alloy reinforced by different ceramic particles. Appl Compos Mater 1(6):431-447 